\title{
Soya isoflavone supplementation enhances spatial working memory in men
}

\author{
Alicia A. Thorp ${ }^{1,2}$, Natalie Sinn ${ }^{1}$, Jonathan D. Buckley ${ }^{1}$, Alison M. Coates ${ }^{1}$ and Peter R. C. Howe ${ }^{1 *}$ \\ ${ }^{1}$ Nutritional Physiology Research Centre and ATN Centre for Metabolic Fitness, Sansom Institute for Health Research, University \\ of South Australia, Adelaide, SA, Australia \\ ${ }^{2}$ School of Molecular and Biomedical Science, University of Adelaide, Adelaide, SA, Australia
}

(Received 11 November 2008 - Revised 17 April 2009 - Accepted 17 April 2009 - First published online 1 June 2009)

Females perform better in certain memory-related tasks than males. Sex differences in cognitive performance may be attributable to differences in circulating oestrogen acting on oestrogen $\beta$ receptors $(E R \beta)$ which are prevalent in brain regions such as the hippocampus, frontal lobe and cortex that mediate cognitive functions. Since soya isoflavones are known to activate ER $\beta$, chronic isoflavone supplementation in males may improve cognitive performance in memory-related tasks. A 12-week double-blind, placebo-controlled cross-over trial was conducted in thirty-four healthy men to investigate the effect of isoflavone supplementation on cognitive function. Volunteers were randomised to take four capsules/d containing soya isoflavones (116 mg isoflavone equivalents/d: $68 \mathrm{mg}$ daidzein, $12 \mathrm{mg}$ genistein, $36 \mathrm{mg}$ glycitin) or placebo for 6 weeks, and the alternate treatment during the following 6 weeks. Assessments of memory (verbal episodic, auditory and working), executive function (planning, attention, mental flexibility) and visual-spatial processing were performed at baseline and after each treatment period. Isoflavone supplementation significantly improved spatial working memory $(P=0.01)$, a test in which females consistently perform better than males. Compared with placebo supplementation, there were $18 \%$ fewer attempts $(P=0.01), 23 \%$ fewer errors $(P=0.02)$ and $17 \%$ less time $(P=0.03)$ required to correctly identify the requisite information. Isoflavones did not affect auditory and episodic memory (Paired Associate Learning, Rey's Auditory Verbal Learning Task, Backward Digit Span and Letter-Number Sequencing), executive function (Trail Making and Initial Letter Fluency Task) or visual-spatial processing (Mental Rotation Task). Isoflavone supplementation in healthy males may enhance cognitive processes which appear dependent on oestrogen activation.

Phyto-oestrogens: Cognitive performance: Diet: Sex differences

Sex differences in cognitive ability are a widely studied and controversial topic. Women have consistently performed better on tests of language ability (word fluency, spelling, grammatical usage) $)^{(1,2)}$ and certain memory tasks (verbal recall of information), while men appear to be superior at mechanical and visual-spatial tasks ${ }^{(3,4)}$.

Social scientists have attributed these differences between sexes to our evolution in which complementary roles as hunters and gatherers placed different selection pressures on specific aspects of cognition ${ }^{(5)}$. There is now compelling evidence that the sex hormone oestrogen and the location of oestrogen $\beta$ receptors (ER $\beta)$ in brain areas such as the hippocampus, frontal lobe and cortex, which play pivotal roles in memory (verbal and visual) and learning function ${ }^{(6-8)}$, are responsible for the differentiation and maintenance of dimorphic sex differences in cognitive function ${ }^{(9-11)}$.

Hormone replacement therapy, in which oestrogen is exogenously supplied, has been consistently shown to enhance and protect memory function in postmenopausal women ${ }^{(12,13)}$. Evidence that it may be possible to enhance the execution in men of cognitive tasks that are naturally performed better by women first arose from a study involving genetically male transsexuals who had been undergoing hormone replacement therapy for several months whilst awaiting gender reassignment surgery ${ }^{(14)}$. The authors of the study reported that, compared with those not on any hormone therapies, men receiving oestrogen showed improved verbal memory performance, a task at which women are generally superior. Visualspatial processing, a task at which men naturally excel, was also preserved in those undergoing therapies, indicating that oestrogen may provide similar cognitive benefits in men as in women without detrimental effects on male-related cognitive processes. However, the use of oestrogen therapy to improve cognitive function in otherwise healthy males is not advocated.

Soya isoflavones such as daidzein and genistein mimic many of the physiological actions of oestrogens due to their high binding affinity for ER $\beta$ without inducing the development of female secondary sex characteristics. Animal studies ${ }^{(15-17)}$ have confirmed that isoflavones, with their similar chemical structure to endogenous oestrogen, can improve cognition via ER $\beta$-mediated events that lead to enhanced brain cell survival, growth and neuroplasticity. Lee et al. specifically demonstrated the ability of isoflavones to improve cholinergic enzyme activity in the brain and increase neuron density, resulting in improved cognitive performance ${ }^{(15)}$. Hence, there has been considerable interest in whether the

Abbreviations: Er $\beta$, oestrogen $\beta$ receptor; PAL, Paired Associate Learning Task; RAVLT, Rey Auditory Verbal Learning Test. 
regular consumption of these isoflavones can provide similar benefits for cognitive performance in males as has been reported for oestrogen therapy.

While some studies in postmenopausal women not undergoing oestrogen therapy indicate that soya isoflavones improve cognitive performance ${ }^{(18-20)}$, others have failed to reproduce the same effects ${ }^{(20-22)}$. Whether isoflavones exert a beneficial effect in males is also debatable. White et al. ${ }^{(23)}$ examined relationships between tofu consumption by healthy middle-aged Japanese-American men living in Oahu and their cognitive performance and brain weight later in life. They observed greater brain atrophy and deterioration in brain function in men who consumed more than two servings of tofu per week. However, the design of their study is open to several criticisms. Even though it provided no direct evidence that brain atrophy and deterioration in cognitive function was due to the isoflavone content of the tofu, it was implied that isoflavones were a contributing factor. Several rodent studies support the claim of White et al. that isoflavone supplementation may be detrimental to cognitive performance in males $^{(17,24)}$, specifically worsening traits such as visual conceptualisation at which males are naturally predisposed to perform better than females.

Of the few human studies that have investigated the effects of soya consumption on cognition in males, all have been conducted using young, healthy populations ${ }^{(25-27)}$, with only one ${ }^{(27)}$ directly correlating effects with isoflavone consumption. This particular study by File et al. found that, compared with a control diet, consumption of a high-soya diet enriched with $100 \mathrm{mg}$ total isoflavones/d for 10 weeks improved immediate and long-term episodic memory, mental flexibility and planning ability in males. However, improvements in cognition were not consistent across sexes, with females improving more at certain cognitive tasks after supplementation and males showing impaired performance in others.

In view of the limited number of studies undertaken to assess the impact of isoflavone supplementation on cognition in males, we aimed to investigate whether regular consumption of isoflavones by healthy men could improve their performance of cognitive tasks that appear dependent on oestrogen, such as memory, without impairing performance of other cognitive tasks in which men are naturally proficient.

\section{Experimental methods}

\section{Subjects}

Forty healthy men aged 30-80 years were recruited from the general community by media, print and electronic advertisements. Eligibility was initially assessed via a phone interview and by a diet and lifestyle screening questionnaire. Volunteers were excluded if they were habitual soya consumers (more than two serves of soya foods per week), suffered from known cognitive impairments or took prescribed medications or over-the-counter supplements that could influence cognition, mood, depression or anxiety.

\section{Study design}

A double-blind, placebo-controlled cross-over supplement intervention trial of 12 weeks' duration was undertaken at the Nutritional Physiology Research Centre, a joint affiliation of the University of South Australia and the University of Adelaide. The protocol for the intervention was approved by, and followed in accordance with, ethical standards of each institution's Human Research Ethics Committee. All participants provided written informed consent before taking part.

Volunteers were block-matched into two groups, balanced for age, and randomised to commence treatment with either an active isoflavone or placebo supplement for the first 6 weeks of the intervention. They then crossed over to the alternate treatments for the remaining 6 weeks. Cognitive assessments were made at baseline and at the end of each treatment phase.

\section{Supplementation}

Encapsulated supplements were produced by Frutarom (Nutrilab B.V., Giessen, The Netherlands) and donated by Soy Health Pty Ltd (Sydney, Australia). Placebo supplements were manufactured as $500 \mathrm{mg}$ capsules and designed to contain $30 \mathrm{mg}$ of raftilose and fibre. Subjects on the active treatment phase consumed four $500 \mathrm{mg}$ capsules of Soy Life $40^{\circledR}$ per $\mathrm{d}$, comprising $116 \mathrm{mg}$ total isoflavones of which $68 \mathrm{mg}$ was daidzein, $12 \mathrm{mg}$ was genistein and $36 \mathrm{mg}$ glycitin. Subjects on the placebo treatment phase consumed four matching placebo capsules/d, comprising $30 \mathrm{mg}$ of fibre and raftilose. They were instructed to consume two capsules in the morning and two at night. All capsules were provided at the commencement of each treatment phase. Volunteers were provided with information on foods and beverages that contain soya and/or isoflavones and advised to abstain from consuming them during the course of the intervention.

Supplementation adherence was determined by counting the number of capsules returned after each 6-week treatment phase.

\section{Cognitive assessments}

All three cognitive testing sessions were conducted after a minimum $6 \mathrm{~h}$ fast from food and minimum $2 \mathrm{~h}$ fast from stimulants (caffeine, alcohol) and other fluids (except water).

Subjects consumed a standardised meal (plain sweet $60 \mathrm{~g}$ cookie and $250 \mathrm{ml}$ orange juice) before commencing the cognitive assessments. The baseline session was designed to familiarise subjects with the test battery which was then repeated after the completion of each 6-week treatment phase. All tests were conducted for a subject at the same time of the day (morning or afternoon) in a quiet environment by an experienced study investigator trained by a research psychologist.

\section{Battery of cognitive tests}

As isoflavones are shown to specifically affect those areas of the brain (hippocampus, frontal lobe and cortex) that control executive mental function, memory and visual-spatial processing, tests that measure these cognitive processes were selected for the intervention. These included tasks on which females perform better than males. For instance, women are repeatedly shown to excel at the Novel Spatial Working Memory Task ${ }^{(28)}$, Paired Associate Learning Task (PAL) ${ }^{(29)}$ and the Rey Auditory Verbal Learning Test (RAVLT) ${ }^{(30,31)}$ 
in comparison with men. These tests appear to be directly influenced by oestrogen, for which women have naturally higher circulating levels, rather than by differences in the integrity of the prefrontal cortex and hippocampal formation which is responsible for executing these tasks ${ }^{(32)}$. Furthermore, to investigate whether performance on male-related tasks was reduced by the intervention, a test of visual-spatial processing was included.

Therefore, the test battery incorporated five memory based tests (the RAVLT ${ }^{(31)}$, PAL ${ }^{(32)}$, Backwards Digit Span ${ }^{(33)}$, Letter-Number Sequencing ${ }^{(33)}$ and Novel Spatial Working Memory ${ }^{(26)}$ ), two tests of executive mental function (Initial Letter Fluency ${ }^{(34,35)}$ and the Trail Making Test $^{(31,36)}$ ) and one test of visual-spatial processing (the Mental Rotation $\operatorname{Task}^{(37)}$.

Summarised in Table 1 are the eight cognitive tests which were performed, a brief description of the specific cognitive function being assessed, the specific region of the brain that pertains to that function and whether the test exhibited any known sex bias.

\section{Tests of memory}

The RAVLT ${ }^{(31)}$ and PAL ${ }^{(32)}$ measure verbal recall memory. In the RAVLT, responders are required to immediately recall a fifteen-word list read aloud by the examiner with five repetitions, then after hearing a distracter list of fifteen words, and again after a $20 \mathrm{~min}$ delay. The PAL similarly tests immediate and delayed auditory recall of words, although additionally assesses the ability to associate unrelated word pairs together.

Spatial working memory was assessed using a novel multitrial task developed by Duff \& Hampson ${ }^{(28)}$. In the Novel Spatial Working Memory Task, testees are required to progressively discover the location of ten pairs of coloured dots concealed in an array of twenty cards (five $\times$ four), in as few choices as possible and in the shortest amount of time possible. Proficient performance in the task is dependent on the ability to maintain and continually update representations of the spatial locations where coloured dots had previously been found in order to identify the location of coloured pairs.

Backwards Digit Span and Letter-Number Sequencing, subsets of the Wechsler Adult Intelligence Scale (WAIS III) ${ }^{(33)}$, were performed to assess auditory working memory. Backwards Digit Span requires testees to recall, in reverse order, a sequence of numbers read aloud to them. In the LetterNumber Sequencing Task, letters and numbers are provided verbally in random order, with responders required to recall first the numbers and then the letters, both in an ascending order.

\section{Tests of executive mental function}

Mental flexibility, attention and planning ability were assessed using Initial Letter Fluency ${ }^{(34,35)}$ and the Trail Making Test ${ }^{(36)}$. The Trail Making Test is administered in two parts. In part A, testees are presented with a piece of paper containing randomly placed numbered (1-25) circles and asked to connect as quickly as possible the circled numbers in their consecutive order, i.e. 1 to 2 to 3 , etc. In part B, testees are given a piece of paper that has both randomly placed numbered $(1-25)$ and lettered $(\mathrm{A}-\mathrm{Y})$ circles and are asked to link the numbered and lettered circles in consecutive order and alternately between the two sequences, i.e. link $A$ to 1 to $\mathrm{B}$ to 2 to $\mathrm{C}$, etc. The time taken to successfully complete part $\mathrm{A}$ and part $\mathrm{B}$ with no errors was recorded (in s) and the difference score (part B - part A) was calculated to remove the element of speed from the evaluation.

Initial Letter Fluency, a shortened version of the Controlled Oral Word Association Test, requires testees to state as many words as possible that begin with a specific letter of the alphabet in $60 \mathrm{~s}$. Testees are instructed that the words must be composed of four or more letters, may not begin with a capital letter (which means excluding words such as people's names, places, brand names, etc), must not be a number and must not be a word they may have previously stated but with a different ending. Scores are based on the number of words recited within $60 \mathrm{~s}$ that comply with the test rules.

\section{Test of visual-spatial processing}

The Mental Rotation Task is a test commonly used to evaluate an individual's ability to mentally rotate visual forms. For the present study, Hay's online Mental Rotation Task was used $^{(33)}$. Participants were shown two different rotations of a multi-faceted object and asked to identify whether the second object was a correct rotation of the first. The number of correct responses and speed of responding (in s) were recorded.

Table 1. Battery of cognitive tests used in the intervention

\begin{tabular}{|c|c|c|c|c|}
\hline Cognitive test & Brain area & Cognitive function & Test duration (min) & Sex bias \\
\hline Novel Spatial Working Memory Task & Prefrontal cortex & $\begin{array}{l}\text { Object and spatial location recall, } \\
\text { working memory }\end{array}$ & 10 & Female \\
\hline Paired Associate Learning Task & Hippocampus & $\begin{array}{l}\text { Declarative memory, learning, auditory } \\
\text { memory recall }\end{array}$ & $5-10$ & Female \\
\hline Backwards Digit Span & Prefrontal cortex & Working memory & $3-5$ & None \\
\hline Letter-Number Sequencing Task & Prefrontal cortex & Working memory & $5-10$ & None \\
\hline Mental Rotation Task & Hippocampus, parietal lobe & Visual-spatial processing & 5 & Male \\
\hline Rey Auditory Verbal Learning Test & Hippocampus & Learning, auditory memory recall & $10-15$ & Female \\
\hline Trail Making Test & Prefrontal cortex, parietal lobe & Planning ability & $3-5$ & None \\
\hline Initial Letter Fluency Task & Frontal lobe & $\begin{array}{l}\text { Spontaneous mental flexibility, strategic } \\
\text { retrieval of verbal information }\end{array}$ & 3 & None \\
\hline
\end{tabular}


Data analysis and statistical considerations

A potential confounder with the repetition of cognitive tests is improvement in performance due to learning or practice. The randomised, balanced cross-over design of the study should prevent any bias due to learning by eliminating order effects. Moreover, only the second and third assessments (the end of each treatment phase) were used for the cross-over comparison, thus eliminating any improvement from the initial baseline test. In any case, in the initial placebo arm, no significant improvement was detected in any test at the second and third assessments compared with the baseline assessment, indicating no evidence of a practice effect.

Data were analysed using STATISTICA for Windows software (version 5.1; StatSoft Inc., Tulsa, OK, USA). Effects of treatment on cognitive test scores were determined by oneway ANOVA with repeated measures using baseline scores as a fixed covariate. Where ANOVA showed significant main effects, differences between means were determined post hoc using Tukey's honestly significant difference test. For the Spatial Working Memory Task with multiple components in its assessment, a one-way multivariate ANOVA with repeated measures was performed to determine an overall effect of treatments on the test. Relationships between dependent variables (age and daily isoflavone intake) were determined using linear regression (SPSS software version 10; SPSS Inc., Chicago, IL, USA). Based on the results of an unpublished pilot study of twenty subjects (AA Thorp,
N Sinn, JD Buckley, AM Coates and PRC Howe, unpublished results), it was calculated that forty participants would give $80 \%$ power to detect significant $(P<0.05)$ improvements in spatial working memory (reductions of $20 \%$ in pairs viewed and $25 \%$ in errors). Statistical significance was set at $P<0.05$. All data are shown as mean values with their standard errors unless otherwise stated.

\section{Results}

\section{Subjects}

Of the forty men initially recruited, thirty-four (aged 49 (SEM 10) years) completed the intervention. Inability to comply with the study protocol ( $n 4)$, change in banned study medication $(n 1)$ and surgery for a medical condition unrelated to the study ( $n$ 1) were the reasons cited by the six subjects who withdrew. Adherence to the active treatment was 92 (SEM 1) \%, equating to a mean increase in daily isoflavone intake of 105 (SEM 9) $\mathrm{mg}$.

\section{Cognitive assessments}

Table 2 describes the absolute and change scores for the eight cognitive tests performed during the active and placebo treatments. One-way multivariate ANOVA with repeated measures revealed a significant overall improvement in performance of the Spatial Working Memory Task while subjects were on the active treatment compared with the placebo $(P=0 \cdot 01)$,

Table 2. Absolute scores for cognitive tests at the end of each treatment period and within-subject changes in scores for all subjects $(n 34)$

(Mean values with their standard errors)

\begin{tabular}{|c|c|c|c|c|c|c|c|}
\hline \multirow[b]{3}{*}{ Cognitive test } & \multicolumn{4}{|c|}{ Treatment } & \multirow[b]{3}{*}{$P \dagger$} & \multirow{2}{*}{\multicolumn{2}{|c|}{ Change }} \\
\hline & \multicolumn{2}{|c|}{ Active } & \multicolumn{2}{|c|}{ Placebo } & & & \\
\hline & Mean & SEM & Mean & SEM & & Mean & SEM \\
\hline \multicolumn{8}{|l|}{ Paired Associate Learning Task (no. of words) } \\
\hline First recall & $2 \cdot 88$ & 0.40 & 2.56 & 0.35 & $0 \cdot 18$ & 0.32 & $0 \cdot 24$ \\
\hline Total recall & $19 \cdot 41$ & 1.46 & $18 \cdot 06$ & 1.46 & $0 \cdot 16$ & 1.35 & 0.94 \\
\hline Delayed recall & 5.50 & 0.37 & $5 \cdot 18$ & 0.39 & 0.24 & 0.32 & 0.27 \\
\hline \multicolumn{8}{|l|}{ Novel Spatial Working Memory Task* } \\
\hline Pairs viewed $\ddagger$ & $56 \cdot 44$ & 2.75 & 68.44 & 5.08 & 0.01 & $12 \cdot 00$ & 4.62 \\
\hline Memory errors§ & $73 \cdot 15$ & $5 \cdot 37$ & 95.09 & 9.43 & 0.02 & 21.94 & 8.54 \\
\hline Time to complete task (s)§ & 344 & 24 & 413 & 37 & 0.03 & 69 & 31 \\
\hline \multicolumn{8}{|c|}{ Rey Auditory Verbal Learning Test (no. of words) } \\
\hline First recall & $7 \cdot 62$ & 0.43 & $7 \cdot 29$ & 0.38 & 0.40 & 0.32 & 0.38 \\
\hline Total recall & $55 \cdot 12$ & 1.49 & $54 \cdot 29$ & 1.60 & 0.47 & 0.82 & $1 \cdot 24$ \\
\hline Immediate recall after distraction $\ddagger$ & $10 \cdot 82$ & 0.57 & $10 \cdot 97$ & 0.51 & 0.71 & -0.15 & 0.39 \\
\hline Delayed recall $(20 \mathrm{~min}) \ddagger$ & $10 \cdot 62$ & 0.65 & $10 \cdot 29$ & 0.58 & 0.48 & 0.32 & 0.45 \\
\hline Initial Letter Fluency Task (no. of words)‡ & $26 \cdot 12$ & 1.30 & $25 \cdot 65$ & 1.20 & 0.63 & 0.47 & 0.96 \\
\hline Backwards Digit Span (no. of words) $\ddagger$ & $7 \cdot 35$ & 0.42 & 6.97 & 0.38 & 0.34 & 0.38 & 0.39 \\
\hline \multicolumn{8}{|l|}{ Trail Making Test (s) } \\
\hline Trial A§ & 29 & 2 & 28 & 1 & 0.31 & -0.5 & 1 \\
\hline Trial B§ & 68 & 4 & 70 & 4 & 0.64 & 2 & 4 \\
\hline Total $(B-A) \S$ & 39 & 4 & 41 & 4 & 0.74 & 2 & 4 \\
\hline Letter-Number Sequencing Task (no. correct)‡ & $10 \cdot 38$ & 0.36 & $10 \cdot 71$ & 0.40 & 0.37 & -0.32 & 0.35 \\
\hline \multicolumn{8}{|l|}{ Mental Rotation Task } \\
\hline Number correct & 24.65 & 0.60 & 24.62 & 0.64 & 0.94 & 0.03 & 0.40 \\
\hline Time to complete task (s)§ & 110 & 9 & 113 & 10 & 0.61 & 3 & 6 \\
\hline
\end{tabular}

* All components of the Novel Spatial Working Memory Task were significantly improved after the isoflavone treatment compared with the placebo treatment $(P<0.05)$.

$\dagger$ Statistical significance was determined post hoc using Tukey's honestly significant difference test.

‡ Larger values reflect better performance.

$\S$ Smaller values reflect better performance. 
with each of the three test components individually shown to significantly improve. On average, males viewed $18 \%$ fewer pairs $(P=0.01)$, conducted $23 \%$ fewer memory errors throughout the test $(P=0.02)$ and took $17 \%$ less time (in s) to complete the task $(P=0.03)$. One-way ANOVA with repeated measures revealed no significant treatment effect with respect to any of the other cognitive tests.

Linear regression showed no significant within-subject correlation between change in age or change in mean daily isoflavone intake and changes in any of the cognitive test scores $(r<0 \cdot 26 ; P>0 \cdot 12)$.

\section{Discussion}

The present intervention provides the first known evidence that isoflavone supplementation in men may significantly improve spatial working memory, a female-dominant cognitive process, without being detrimental to the performance of visual-spatial processing, a male-dominant cognitive task. Spatial working memory relates to one's ability to temporarily store and hold location information for an object in a readily assessable form, while other cognitive decisions or operations are taking place, and to manipulate that information or use it to guide action.

These findings support previous data from File et al. who reported improvements in cognitive performance when young males consumed isoflavones ${ }^{(27)}$. They also contradict controversial epidemiological data from White et al. who stated that isoflavones from tofu consumed during midlife can manifest cognitive impairment in males ${ }^{(23)}$.

In the present study, the age of males ranged considerably from 30 to 80 years but was not shown to influence the degree to which their spatial working memory improved. This contradicts the recent findings of Hogervorst et al. ${ }^{(34)}$ that isoflavones present in soya foods worsen memory performance of older but not younger adults.

The improvement observed in the Novel Spatial Working Memory Task may be due to increased binding of isoflavones to ER $\beta$ in the prefrontal cortex, an area of the brain which plays a critical role in working memory ${ }^{(35)}$. Neuroendocrine research confirms that the cortex is highly susceptible to the organisational and activation effects of sex hormones ${ }^{(36-38)}$, with the prefrontal cortex shown to be one of the highest binding sites for oestrogen ${ }^{(39)}$ and its activity associated with variations in female hormonal status ${ }^{(40)}$. Whilst it was beyond the scope of the intervention to assess the entry of isoflavones into specific cerebral regions, their ability to rapidly enter the lipophilic environment of the brain is well established. Gamache et al. ${ }^{(41)}$ was the first to demonstrate that intra-peritoneal injections of genistein and daidzein to adult Sprague-Dawley rats resulted in increased levels in the brain tissue. Animal studies examining the relative isoflavone content of specific brain structures, after feeding an isoflavone-rich diet, have furthermore established that they are most concentrated in regions that are abundant in ER $\beta^{(24,42)}$.

The Novel Spatial Working Memory Task used in the intervention was directly modelled on past tests measuring working memory in which prefrontal involvement has been determined unequivocally ${ }^{(43-46)}$. Women are traditionally shown to view fewer pairs, make fewer mental errors and require less time to complete the task compared with males, with no evidence to suggest that this sex difference in performance is attributable to differences in overall ability, attention, perceptual speed or speed of verbal access. In the present intervention, all of our male subjects viewed significantly fewer pairs $(18 \%)$, made fewer mental errors $(23 \%)$ and performed the task in a shorter amount of time $(17 \%)$ after receiving isoflavone supplementation.

In contrast to our predictions, the two other cognitive tasks (PAL and RAVLT) that are known to be performed naturally better by females did not improve. With only a small number of male subjects completing the trial ( $n$ 34), this sample size may have been underpowered to detect a significant effect in a healthy population. For instance, the Novel Spatial Working Memory Task is specifically devised to be sensitive enough to detect significant improvements in healthy adults, whereas the PAL and RAVLT tests were both developed to detect differences in populations who have known or severe cognitive impairments. Moreover, the sex difference in performance of the Spatial Working Memory Task is typically greater than the observed sex difference in other cognitive tests $^{(28)}$, so it is not surprising that this was the only test to show improvement in males in the present study.

Three tests in our cognitive battery known to have no sex difference (Letter-Number Sequencing Task, Initial Letter Fluency Task and the Backward Digit Span Task) ${ }^{(47-50)}$ were also shown to be unaffected by isoflavone treatment, which is similar to the lack of effect seen in postmenopausal women consuming $99 \mathrm{mg}$ isoflavone/d for 12 months $^{(51)}$ and $70 \mathrm{mg}$ total isoflavones for 16 weeks $^{(52)}$. Overall, the Trail Making Test is not considered to be sex biased. However, there is evidence that women may perform somewhat slower than men on part $\mathrm{B}^{(53)}$. Part $\mathrm{B}$ of the Trail Making Test is shown to be more sensitive to cognitive flexibility than part $A$ and places increased demands on motor speed and visual $\operatorname{search}^{(54,55)}$. In the intervention, the time taken to complete part B of the Trail Making Test did not differ for subjects during each of the treatments, suggesting that the isoflavones were not detrimental to the men's performance of this task.

In visual-spatial processing tasks that require the ability to perceive, analyse, synthesise, and think with non-linguistic visual patterns and spatial configurations, researchers have consistently found that males outperform females ${ }^{(56-59)}$. The underlying mechanism for this difference is not fully understood though there is strong evidence to suggest that gonadal steroids modulate this sexually dimorphic ability, specifically testosterone through interneuronal conversion to oestradiol in the brain ${ }^{(60)}$. For instance, the castration of male rats is shown to inhibit visual-spatial performance, whilst treatment of intact and ovariectomised female rats with testosterone improves their spatial ability ${ }^{(61,62)}$. Several animal studies have investigated the effect of isoflavones on cognitive tasks that favour males, such as visual-spatial processing, using the Mental Rotation Task ${ }^{(63)}$. Two studies found that consumption of isoflavones was detrimental to performance of the Mental Rotation Task in male rats compared with females ${ }^{(17,24)}$. In contrast, elderly male rats consuming a high-isoflavone diet have been reported to exhibit improved spatial memory in a delayed matching-to-place water maze task ${ }^{(15)}$.

In the present intervention, performance of the Mental Rotation Task was consistent across the treatments. A lack of difference indicates that our men's visual-spatial performance was not adversely affected by isoflavone supplementation and 
contradicts previous evidence in animal models that isoflavones are harmful to this specific cognitive function in males.

Despite predicting sufficient power with forty male subjects, only one of the eight tests showed a significant improvement following supplementation of isoflavones. An explanation for this could be that the thirty-four males in the intervention had no apparent impairment in their cognitive function and a greater number of subjects would be needed to detect significant improvements in a healthy population. A further limitation of the intervention was our inability to control potential hormonal effects, with evidence that testosterone levels fluctuate during the day and can influence the cognitive performance of males ${ }^{(64-66)}$. Whilst subjects attended the clinic at the same time of day after each treatment, no blood samples were collected before testing. Subsequently it was not possible to quantify subjects' testosterone levels and use this as a covariate in our analysis of their cognitive performance. Compliance of participants in the study is also subject to criticism. Adopting a more robust method such as assessing $24 \mathrm{~h}$ urinary isoflavone levels as opposed to capsule counting would have improved the accuracy of the assessment.

In summary, when healthy men consumed isoflavones, an improvement in spatial working memory was observed. This type of cognitive process is traditionally performed better by females because of the sex hormone, oestrogen. The test used to assess this cognitive function was the Novel Spatial Working Memory Task. An improvement in all aspects of this multicomponent test denotes an enhanced ability by the men to retain and continually update information based on visual cues. It is speculated that the ability of isoflavones to bind to $\mathrm{ER} \beta$ and mediate transcriptional events that enhance neuronal growth, survival and synaptogenesis in the prefrontal cortex may have instigated the effect. Importantly, isoflavones were not shown to be detrimental to the performance of visual-spatial processing, a task at which males naturally excel.

\section{Acknowledgements}

The present study was supported by Frutarom (Nutrilab B.V., Giessen, The Netherlands) and Soy Health Pty Ltd (Sydney, Australia). Frutarom and Soy Health Pty Ltd donated the isoflavone and placebo capsules used in the study.

A. A. T. and P. R. C. H. initiated, designed, and attracted support for the study; N. S. designed the battery of cognitive tests used in the study and trained A. A. T. to administer the tests; A. A. T. recruited subjects and conducted the study visits. P. R. C. H., A. M. C. and J. D. B. supervised the study visits; A. A. T., N. S. and J. D. B. undertook statistical analyses; A. A. T. prepared the manuscript and the other authors all reviewed and contributed to the manuscript.

None of the authors has a potential conflict of interest.

\section{References}

1. Kimura D (1999) Sex and Cognition. Cambridge, MA: The MIT Press.

2. Mann VA, Sasanuma S, Sakuma N, et al. (1990) Sex differences in cognitive abilities: a cross-cultural perspective. Neuropsychologia 28, 1063-1077.

3. Maccoby EE \& Jacklin CN (1974) The Psychology of Sex Differences. Stanford, CA: Stanford University Press.
4. Collaer ML \& Hines M (1995) Human behavioral sex differences: a role for gonadal hormones during early development? Psychol Bull 118, 55-107.

5. Silverman I \& Phillips K (1998) The evolutionary psychology of spatial sex differences. In Handbook of Evolutionary Psychology: Ideas, Issues and Applications, pp. 595-611 [C Crawford and DL Krebs, editors]. Mahwah, NJ: Erlbaum.

6. Shughrue PJ, Lane MV \& Merchenthaler I (1997) Comparative distribution of estrogen receptor- $\alpha$ and $-\beta$ mRNA in the rat central nervous system. J Comp Neurol 388, 507-525.

7. Osterlund MK \& Hurd YL (2001) Estrogen receptors in the human forebrain and the relation to neuropsychiatric disorders. Prog Neurobiol 64, 251-267.

8. Pau CY, Pau KY \& Spies HG (1998) Putative estrogen receptor $\beta$ and $\alpha$ mRNA expression in male and female rhesus macaques. Mol Cell Endocrinol 146, 59-68.

9. Otto T \& Eichenbaum H (1992) Neuronal activity in the hippocampus during delayed non-match to sample performance in rats: evidence for hippocampal processing in recognition memory. Hippocampus 2, 323-334.

10. Loy R, Gerlach JL \& McEwen BS (1988) Autoradiographic localization of estradiol-binding neurons in the rat hippocampal formation and entorhinal cortex. Brain Res 467, 245-251.

11. O'Keefe JA \& Handa RJ (1990) Transient elevation of estrogen receptors in the neonatal rat hippocampus. Brain Res Dev Brain Res 57, 119-127.

12. Duff SJ \& Hampson E (2000) A beneficial effect of estrogen on working memory in postmenopausal women taking hormone replacement therapy. Horm Behav 38, 262-276.

13. Maki PM, Zonderman AB \& Resnick SM (2001) Enhanced verbal memory in nondemented elderly women receiving hormonereplacement therapy. Am J Psychiatry 158, 227-233.

14. Miles C, Green R, Sanders G, et al. (1998) Estrogen and memory in a transsexual population. Horm Behav 34, 199-208.

15. Lee YB, Lee HJ, Won MH, et al. (2004) Soy isoflavones improve spatial delayed matching-to-place performance and reduce cholinergic neuron loss in elderly male rats. J Nutr 134, 1827-1831.

16. File SE, Hartley DE, Alom N, et al. (2003) Soya phytoestrogens change cortical and hippocampal expression of BDNF mRNA in male rats. Neurosci Lett 338, 135-138.

17. Lephart ED, West TW, Weber KS, et al. (2002) Neurobehavioral effects of dietary soy phytoestrogens. Neurotoxicol Teratol 24, 5-16.

18. File SE, Hartley DE, Elsabagh S, et al. (2005) Cognitive improvement after 6 weeks of soya supplements in postmenopausal women is limited to frontal lobe function. Menopause 12, 193-201.

19. Duffy RH, Wiseman H \& File SE (2003) Improved cognitive function in postmenopausal women after 12 weeks of consumption of a soya extract containing isoflavones. Pharmacol Biochem Behav 75, 721-729.

20. Kritz-Silverstein D, Von Mühlen D, Barrett-Connor E, et al. (2003) Isoflavones and cognitive function in older women: the SOy and Postmenopausal Health In Aging (SOPHIA) Study. Menopause 10, 196-202.

21. Kreijkamp-Kaspers S, Kok L, Bots ML, et al. (2005) Randomized controlled trial of the effects of soy protein containing isoflavones on vascular function in postmenopausal women. Am J Clin Nutr 81, 189-195.

22. Ho SC, Chan AS, Ho YP, et al. (2007) Effects of soy isoflavone supplementation on cognitive function in Chinese postmenopausal women: a double-blind, randomized, controlled trial. Menopause 14, 489-499.

23. White LR, Petrovitch H, Ross GW, et al. (2000) Brain aging and midlife tofu consumption. J Am Coll Nutr 19, 242-255.

24. Lund TD, West TW, Tian LY, et al. (2001) Visual spatial memory is enhanced in female rats (but inhibited in males) by dietary soy phytoestrogens. BMC Neurosci 2, 20. 
25. Celec P, Ostatníková D, Hodosy J, et al. (2007) Increased one week soybean consumption affects spatial abilities but not sex hormone status in men. Int J Food Sci Nutr 58, 424-428.

26. Ostatníková D, Celec P, Hodosy J, et al. (2007) Short-term soybean intake and its effect on steroid sex hormones and cognitive abilities. Fertil Steril 88, 1632-1636.

27. File SE, Jarrett N, Fluck E, et al. (2001) Eating soya improves human memory. Psychopharmacology (Berl) 157, 430-436.

28. Duff SJ \& Hampson E (2001) A sex difference on a novel spatial working memory task in humans. Brain $\operatorname{Cogn} 47$, 470-493.

29. Ivison D (1977) The Wechsler Memory Scale: preliminary findings toward an Australian standardisation. Aust Psychol 12, 303-312.

30. Bleecker ML, Bolla-Wilson K, Agnew J, et al. (1988) Agerelated sex differences in verbal memory. J Clin Psychol 44, 403-411.

31. Geffen GM, Moar KJ, O'Hanlon AP, et al. (1990) The Auditory Verbal Learning Test (Rey): performance of 16 to 86 year olds of average intelligence. Clin Neuropsychol 4, 45-63.

32. Berenbaum SA, Baxter L, Seidenberg M, et al. (1997) Role of the hippocampus in sex differences in verbal memory: memory outcome following left anterior temporal lobectomy. Neuropsychology 11, 585-591.

33. Hay JC (2007) PsychLab Online: 2D Mental Rotation Task. http://pantherfile.uwm.edu/johnchay/index.htm?uniq $=1 \mathrm{n} 12 \mathrm{ul}$

34. Hogervorst E, Sadjimin T, Yesufu A, et al. (2008) High tofu intake is associated with worse memory in elderly Indonesian men and women. Dement Geriatr Cogn Disord 26, 50-57.

35. Courtney SM, Petit L, Maisog JM, et al. (1998) An area specialized for spatial working memory in human frontal cortex. Science 279, 1347-1351.

36. Bonsall RW, Zumpe D \& Michael RP (1990) Comparisons of the nuclear uptake of $\left[{ }^{3} \mathrm{H}\right]$-testosterone and its metabolites by the brains of male and female macaque fetuses at 122 days of gestation. Neuroendocrinology 51, 474-480.

37. Clark AS, MacLusky NJ \& Goldman-Rakic PS (1988) Androgen binding and metabolism in the cerebral cortex of the developing rhesus monkey. Endocrinology 123, 932-940.

38. MacLusky NJ, Naftolin F \& Goldman-Rakic PS (1986) Estrogen formation and binding in the cerebral cortex of the developing rhesus monkey. Proc Natl Acad Sci U S A 83, $513-516$

39. Bixo M, Bäckström T, Winblad B, et al. (1995) Estradiol and testosterone in specific regions of the human female brain in different endocrine states. J Steroid Biochem Mol Biol 55, 297-303.

40. Berman KF, Schmidt PJ, Rubinow DR, et al. (1997) Modulation of cognition-specific cortical activity by gonadal steroids: a positron-emission tomography study in women. Proc Natl Acad Sci U S A 94, 8836-8841.

41. Gamache PH, Maher TJ, Setchell KDR, et al. (1996) The transfer of non-steroidal dietary estrogens into brain. Soc Neurosci 22, 771-776.

42. Lephart ED, Thompson JM, Setchell KD, et al. (2000) Phytoestrogens decrease brain calcium-binding proteins but do not alter hypothalamic androgen metabolizing enzymes in adult male rats. Brain Res 859, 123-131.

43. Passingham RE (1985) Memory of monkeys (Macaca mulatta) with lesions in prefrontal cortex. Behav Neurosci 99, 3-21.

44. Owen A, Downes JJ, Sahakian BJ, et al. (1990) Planning and spatial working memory following frontal lobe lesions in man. Neuropsychologia 28, 1021-1034.

45. Owen AM, Sahakian BJ, Semple J, et al. (1995) Visuospatial short-term recognition memory and learning after temporal lobe excisions, frontal lobe excisions or amygdalohippocampectomy in man. Neuropsychologia 33, 1-24.
46. Owen AM, Evans AC \& Petrides M (1996) Evidence for a twostage model of spatial working memory processing within the lateral frontal cortex: a positron emission tomography study. Cereb Cortex 6, 31-38.

47. Ruff RM, Light RH, Parker SB, et al. (1996) Benton Controlled Oral Word Association Test: reliability and updated norms. Arch Clin Neuropsychol 11, 329-338.

48. Sarno MT, Buonaguro A \& Levita E (1985) Gender and recovery from aphasia after stroke. J Nerv Ment Dis 173, 605-609.

49. Zec RF, Andrise A, Vicari S, et al. (1990) A comparison of phonemic and sematic word fluency in Alzheimer patients and elderly controls (abstract). J Clin Exp Neuropsychol 12, 18.

50. Blum JE, Fosshage JL \& Jarvik LF (1972) Intellectual changes and sex differences in octogenarians: a twenty year longitudinal study of aging. Dev Psychol 7, 178-187.

51. Kreijkamp-Kaspers S, Kok L, Grobbee DE, et al. (2004) Effect of soy protein containing isoflavones on cognitive function, bone mineral density, and plasma lipids in postmenopausal women: a randomized controlled trial. JAMA 292, 65-74.

52. Fournier LR, Ryan Borchers TA, Robison LM, et al. (2007) The effects of soy milk and isoflavone supplements on cognitive performance in healthy, postmenopausal women. $J$ Nutr Health Aging 11, 155-164.

53. Bornstein RA (1985) Normative data on selected neuropsychological measures from a non clinical sample. J Clin Psychol 41, $651-659$.

54. Kortte KB, Horner MD \& Windham WK (2002) The Trail Making Test, part B: cognitive flexibility or ability to maintain set? Appl Neuropsychol 9, 106-109.

55. Gaudino EA, Geisler MW \& Squires NK (1995) Construct validity in the Trail Making Test: what makes part B harder? J Clin Exp Neuropsychol 17, 529-535.

56. Luine VN, Richards ST, Wu VY, et al. (1998) Estradiol enhances learning and memory in a spatial memory task and effects levels of monoaminergic neurotransmitters. Horm Behav 34, 149-162.

57. Bimonte HA \& Denenberg VH (1999) Estradiol facilitates performance as working memory load increases. Psychoneuroendocrinology 24, 161-173.

58. Berry B, McMahan R \& Gallagher M (1997) Spatial learning and memory at defined points of the estrous cycle: effects on performance of a hippocampal-dependent task. Behav Neurosci 111, 267-274.

59. Williams CL \& Meck WH (1991) The organizational effects of gonadal steroids on sexually dimorphic spatial ability. Psychoneuroendocrinology 16, 155-176.

60. Lephart ED (1996) A review of brain aromatase cytochrome P450. Brain Res Brain Res Rev 22, 1-26.

61. Isgor C \& Sengelaub DR (1998) Prenatal gonadal steroids affect adult spatial behavior, CA1 and CA3 pyramidal cell morphology in rats. Horm Behav 34, 183-198.

62. Roof RL (1993) Neonatal exogenous testosterone modifies sex difference in radial arm and Morris water maze performance in prepubescent and adult rats. Behav Brain Res 53, 1-10.

63. Voyer D, Voyer S \& Bryden MP (1995) Magnitude of sex differences in spatial abilities: a meta-analysis and consideration of critical variables. Psychol Bull 117, 250-270.

64. Fonda SJ, Bertrand R, O'Donnell A, et al. (2005) Age, hormones, and cognitive functioning among middle-aged and elderly men: cross-sectional evidence from the Massachusetts Male Aging Study. J Gerontol A Biol Sci Med Sci 60, 385-390.

65. Moffat SD, Zonderman AB, Metter EJ, et al. (2002) Longitudinal assessment of serum free testosterone concentration predicts memory performance and cognitive status in elderly men. $J$ Clin Endocrinol Metab 87, 5001-5007.

66. Yaffe K, Liu LY, Zmuda J, et al. (2002) Sex hormones and cognitive function in older men. $J$ Am Geriatr Soc 50, 707-712. 